strophanthin as form the most striking feature of action on the heart perfused with Ringer's solution.

There are, therefore, sufficient grounds for ascribing the change in the reaction of the perfused animal heart to malnutrition. Are we justified in drawing an analogy to the human heart in auricular fibrillation? Is the fundamental factor here the malnutrition, the auricular fibrillation only a secondary one? There are some grounds in support of this view. Thus in two cases in which there was normal rhythm in man we obtained slowing and block from digitalis, and these proved to be due to direct action, for they were not removed by atropine. Thus the human heart can give the anomalous reaction even when the rhythm is previously normal. On the other hand, some cases of auricular fibrillation in man fail to give the anomalous reaction. It is therefore proved that this reaction is not inseparably attached to auricular fibrillation. And there is, on the other hand, evidence that the heart muscle is gravely injured in cases of fibrillation. Thus the irregularity is greater than is accounted for by the fibrillation alone. And the absence of proportion between the strength of the individual beats and the duration of the preceding interval has been ascribed to a condition of the heart fibre somewhat analogous to that which gives rise to the pulsus alternans. There is therefore justification for the view that in the human heart also the essential character is not the auricular fibrillation but the underlying weakness of the heart muscle.

I do not mean to suggest that this debilitated state of the heart is the sole ground for the anomalous digitalis reaction, and that the auricular fibrillation is an altogether in dependent feature. For if this were the case, it would be impossible to explain why this reaction occurs so frequently in auricular fibrillation and so seldom in other forms of cardiac debility.

The connexion may be somewhat as follows. In extreme malnutrition of the heart, such as is seen in the perfused rabbit's heart, the anomalous digitalis reaction is elicited without fibrillation. In man this state is comparatively seldom seen while the rhythm is of the normal type, but the onset of auricular fibrillation often induces it. That auricular fibrillation is capable of aggravating greatly any inefficiency already present is obvious. For in normal rhythm there is a measured sequence of events, and due time is given for the recovery of the ventricle from its contraction. In fibrillation a constant storm of impulses beats on the ventricle, it has no longer time to recover from its contractions, and the previous debility is aggravated. In addition, the smaller efficiency of the heart in this rhythm is shown by the marked fall in blood pressure, and this must further tend to impair the hardpressed heart.

The view I would present is that the anomalous reaction of digitalis arises from malnutrition of the heart primarily, but that this state of malnutrition is exaggerated by the demands made on the heart in auricular fibrillation, which thus contributes to the debility and leads to the anomalous reaction secondarily.

In some cases of well-marked auricular fibrillation digitalis has little effect in slowing the pulse, and in these the condition of the heart is less serious. Here there is unquestionably a certain degree of malnutrition, but the ventricle is protected by imperfect conduction from the mob of impulses from the auricle, and the extreme malnutrition which accompanies the very rapid pulse of typical auricular fibrillation is not developed. Digitalis, therefore, does not produce the anomalous reaction.

In the account I have given of the action of digitalis in auricular fibrillation the effective action is the blocking of impulses from the auricle. Another result of digitalis on the animal heart is the increase in the strength of contraction. Does this play no part in the improved efficiency of the heart? This cannot be answered at present, as we have no means of measuring accurately the contraction of the human heart. Undoubtedly the movement is stronger, but this may be due to the slower beat, which allows of a better recovery in the period of rest. In the perfused animal heart the systolic increase occurs at least as soon as the lessened conduction, and this seems evidence in favour of the improved circulation in patients also depending in part on the increase of systole. But the argument, I admit, is not convincing, since in perfusion experiments the dose of digitalis is necessarily larger than that used in man in order to bring on the action within the time-limits of an experiment.

\section{THE TREATMENT OF SOME COMMON WAR NEUROSES.}

BY E. D. ADRIAN, M.R.C.P. LOND.,

TEMPORARY CAPTAIN, R.A.M.C. ; NEUROLOGIST, CONNAUGHT HOSPITAL, ALDERSHOT:

AND

L. R. YEALLAND, M.D.,

RESIDENT MEDTCAL OFFICER, NATIONAL HOSPITAY FOR THE PARALYSED AND EPILEPTIO, QUEEN SQUARE, LONDON.

THE war neuroses with which we are concerned are those in which the patient suffers from some objective disorder such as paralysis, loss of speech, \&c., without showing any signs of organic change in the central nervous system. These disorders often occur as the result of mental and physical exhaustion, violent explosions, \&c., and they often constitute a very serious disability. They form a welldefined group which is readily distinguished from the neurasthenic and psychasthenic conditions where the patients have subjective complaints, headaches, feelings of exhaustion and depression, and very little in the way of physical signs; at the same time it is a difficult matter to find a suitable name for them. Were it not for the stigma attaching to the word, one would not hesitate to class them as hysterical. However, a diagnosis of hysteria is often held to mean that the patient has nothing the matter with him and requires no treatment. This is manifestly absurd in the case of a man who has been stone deaf for months; his disability is real enough and is in urgent need of treatment. As a rule the difficulty can be overcome by speaking of the disorder as functional rather than hysterical. However, the objection to the term functional is that it covers too wide a field. It applies to any condition which has no demonstrable organic basis, and it would include such disorders as neurasthenia and even epilepsy. We need some name for the neurosis which results in the production of objective signs simulating those due to organic disease, and for the present hysteria is the only term we can use. Babinski has coined a word, pithiatism, to take its place, but the word has not yet won acceptance and for the present we have been forced to adhere to the term hysteria in spite of its manifest disadvantages.

The object of this paper is to describe a method which we have found to be extremely useful in dealing with this type of war neurosis. It has been applied in upwards of 250 cases which have included all the most common types of hysterical disorder; we have records of 82 cases of mutism, 34 of deafness, 18 of aphonia, 37 of monoplegia of the arm or leg, 46 of paraplegia, 16 of hemiplegia, and 18 of disordered gaits not associated with organic change. The majority of the cases have been of several months' standing, but in spite of this the treatment has been almost immediately successful in at least 95 per cent. of the cases in which it has been applied.

The method is certainly not new, indeed it is probably employed in some measure by all who have had much to do with functional disorders, and recently several French neurologists have called attention to its value in the treatment of military cases. ${ }^{1}$ However, very little reference has been made to it in recent English literature, and it is not easy to find any comprehensive account of the treatment of disorders of the hysterical type in the average text-book of medicine or even of neurology. At most we find a few lines devoted to the subject of treatment, and we are left with the impression that our task is at an end when we have succeeded in establishing the diagnosis. In war-time this is obviously not enough: adequate treatment is essential, and it will make all the difference between a useless burden to the State and a useful civilian or even a useful soldier.

It is quite true that a correct (or rather a confident) diagnosis is the first step. Indeed, the most important part in the treatment of a functional case consists in making up one's mind that the case is functional. To do this presupposes a knowledge of the signs of organic nervous disease

1 Vincent: Le Traitement des Phènomènes Hystériques par la Ré-éducation Intensive, Tours, 1916. Babinski et Froment: HystériePithiatisme, \&c., Paris, 1917. Rosanoff-Saloff : Considération Générales sur la Camptocormie. Nouvelle Iconographie de la Salpêtrière, 1916-1917. 
and the points of distinction between functional and organic disorders. However, these have been described often enough, and it is our impression that failure in dealing with these cases is as often due to inadequate treatment as to incorrect diagnosis. For this reason we have dealt with the subject of treatment in some detail and have not attempted to discuss points of diagnosis.

The method to be discussed has the advantage that it does not require any special experience (other than that needed to establish the diagnosis), and only demands a certain degree of confidence on the part of the operator. When properly carried out it is extremely rapid and almost invariably successful, even in cases which have been treated by other methods for months or years without result. The method has its limitations, and in particular it does not apply to the exhausted, neurasthenic type of patient who complains of headache, insomnia, \&c., and has no physical symptoms, but only to that type of neurosis where the disability is some objective symptom, paralysis, loss of speech, \&c.

\section{The Aims of Treatment.}

The different forms of treatment in vogue can be best understood by considering the mental characteristics of patients suffering from this form of neurosis. Though it may seem unjustified to make a psychiatric grouping of these cases, yet there are certain mental abnormalities which are present to some extent in nearly every patient. Indeed, anyone visiting hospital wards where functional and organic cases are treated together cannot fail to be struck by the great difference in the mental outlook of the two classes. The chief phenomena underlying the hysterical type of mind are weakness of the will and of the intellect, nypersuggestibility and negativism. The majority of patients are below the average normal intelligence as judged by the Binet-Simon scale, and others who are more highly equipped prove to have an unstable history either personally or in the family. Their hypersuggestibility is shown by the mode of production of their symptoms and by the ease with which the physician can suggest such conditions as anæsthesia, contraction of the visual fields, \&c. At the same time there is a pronounced element of negativism which may amount to a mere inertia or to an active, but not necessarily a conscious, resistance to the idea of recovery. Conditions of negativism are often seen on attempts at movement when the antagonistic muscles overact, when the patient moves backwards when he is told to move forwards, c. The unconscious resistance is often well marked and must be broken down before any results can be obtained. A combination of hypersuggestibility and negativism may seem to imply a contradiction, but the two are not difficult to reconcile. The patient has a fixed idea that he is dumb or paralysed and he resists all criticism of this idea, but outside this he responds to external suggestions much more readily than a normal person. Indeed, the fixed idea is developed as the result of auto-suggestions acting on a mind enfeebled by fear and emotional tension and this autosuggestion becomes so strong that the patient resists all attempts to undermine his fixed belief.

These facts are important because they show that we must take into account two distinct conditions in considering treatment and prognosis. These are (a) the fixed idea which is giving rise to the functional symptom, paralysis, loss of speech, and so forth, and $(b)$ the state of mind which has allowed this fixed idea to develop. The fixed idea can be treated successfully by suggestive methods and the patient can be restored to apparent health, but there is no reason to suppose that his mental instability will vanish. He will always be liable to develop hysterical troubles in moments of emotional stress and exhaustion, just as a man with a malformed chest will be liable to attacks of bronchitis. As Pitres said: "En réalité on nait hystérique, on ne le devient pas."

\section{Psyoho-analysis.}

There is, however, one method of treatment which lays claim to the power of curing not only the hysterical symptoms but also the hysterical mentality. This is the method of psycho-analysis which is based on the idea that the hysterical type of mind is the result of a buried and unfulfilled wish dating from early infancy and concerned with some fundamental sexual longing. The idea was suppressed because it came into conflict with accepted notions of morality and conduct and its repression has led to a permanent state of tension and unconscious mental conflict. The hysterical symptom is supposed to be simply the emotional expression of the repressed desire or of some secondary conflict due to this desire. When the original infantile desire has been unearthed and explained to the patient, the repressed conflict will vanish and with it not only the hysterical symptom but also the state of mind which made this symptom possible.

It is difficult to avoid the belief that suggestion must play a large part in the cure of those cases where the treatment is successful, but it is not easy to judge of the merits of psycho-analysis because its tenets seem to call either for whole-hearted approval or else for whole-hearted abuse, and the middle course is deplored by both parties, However, the method has certain obvious disadvantages, even though we accept everything which has been said in its favour. It entails a considerable degree of training on the part of the operator, and a considerable degree of intelligence on the part of the patient, and it is a process which demands a great deal of time and individual attention. Indeed, the course of treatment may run into years if a serious attempt is made to cure the hysterical mind by purging it of all the accumulated filth of a lifetime; and if the analysis is not carried through as thoroughly as this the state of tension will remain in some degree and the treatment will have little advantage over the much more rapid methods which are concerned only with the alleviation of the immediate symptoms. Whether the result would justify a lengthy psycho-analysis is another matter, but in any case the time at our disposal is not unlimited, and for this reason alone the treatment is best left to special hospitals dealing with specially selected cases.

\section{Treatment of Symptoms.}

We may pass on, then, to consider those methods of treatment which aim only at relieving the functional symptoms and do not profess to give the patient a new mind. There are three principles involved in all these methods-namely, (1) suggestion, (2) re-education, and (3) discipline. The aim of suggestion is to make the patient believe he will be cured, and to lead him on from this to the belief that he is cured. Re-education brings the disordered function back to the normal by directing it until the bad habit is lost, and disciplinary treatment breaks down the unconscious resistance of the patient to the idea of recovery.

One might add a fourth line of treatment, which consists in adopting the attitude of Mr. Micawber and waiting for something to turn up. Probably this course is often adopted because there is some doubt as to the diagnosis. When it is uncertain whether a paralysis is functional or organic it is perhaps natural enough to leave it alone in the hope that time will show the difference. Fortunately, a certain number of functional cases do recover when left to themselves, but a large number do not, and expectant treatment may keep a patient for six months in hospital when more vigorous measures would have removed his symptoms in a week. Moreover, the atmosphere of a hospital is distinctly enervating and a functional case is rarely the better for a prolonged stay in the wards even though the symptoms may have improved.

\section{Hypnotism.}

As an example of a process which aims at curing by pure suggestion we may instance treatment by hypnotism. The treatment consists in reducing the patient to a state of mind in which his critical faculties are in abeyance and then suggesting verbally that his disability no longer exists. Most hysterical patients, being hyper-suggestible, are very easy to hypnotise lightly. They will readily accept the idea that they cannot open their eyes or move their limbs and they will comply with any suggestion which does not relate to their disability. Unfortunately they are not nearly so tolerant when the suggestion touches their fixed belief that they cannot speak or that their legs are paralysed, and it requires a far greater ascendancy on the part of the operator before they will agree to suggestions which are curative and not merely ornamental. One has only to be hypnotised to realise this state of mind. Unimportant suggestions are readily accepted, but anything which runs counter to one's favourite prejudices is simply dismissed as absurd. With a patient who is intelligent and anxious to get well hypnotism may be extremely successful, and it is certainly of great value in the treatment of subjective troubles such as 
insomnia, fighting dreams, \&c. ${ }^{2}$ which can scarcely be classed as hysterical. However, in the majority of functional cases where the resistance is at all marked our limited experience of the method has led us to believe that it is slow and uncertain in comparison with vigorous suggestive treatment and re-education.

Isolation.

As an example of treatment in which the disciplinary element is very much to the fore we may instance the use of strict isolation in hysterical cases. This supplies the needful stimulus to recovery by making the patient's illness a dreary and unprofitable business instead of a source of pride and satisfaction. For this reason it is extremely useful in cases of functional tremors and pseudo-chorea where the patient becomes quiet as soon as he is deprived of his audience. It is not suggested that isolation acts in this way in every functional disorder. The frightened, exhausted neurasthenic is often much happier when left to himself with nothing to disturb him, and it would be absurd to regard isolation as a disciplinary measure in such cases. But in those cases where disciplinary measures seem to be indicated we doubt if isolation is an advisable form of treatment. It may eventually force a patient to release his claim to a supposed disorder, but the process may take some time and is rarely as effective as a little plain speaking accompanied by a strong faradic current. Moreover, eight hours' rest out of the 24 is, to our mind, quite sufficient, and extension of that time in one who has no indication of physical illness is more liable to do harm than good. The disciplinary element may be assumed to enter into any form of painful suggestive treatment; it is often unnecessary, particularly in those cases where the disability is irksome enough by itself and the patient is anxious to get well ; but in many cases it is a very important part of the treatment since it is the only certain means of breaking down the patient's resistance to the idea of recovery.

Under the heading of re-education we might include the method of simple persuasion in which the patient is convinced by logical argument that his condition is not so serious as he supposes. ${ }^{3}$ The difficulty with this form of treatment lies in the fact that a patient of average intelligence does not easily realise that his physical disability is due to a mental and not to a physical disorder. If an attempt is made to explain the real state of affairs to him he is generally left with the impression that he is suspected of malingering. It seems only natural to him that his cure should be brought about by some physical means, and therefore he will respond to some simple suggestive measure when persuasion or re-education would leave him untouched. In certain cases, notably in mutism and aphonia and in the spastic type of paraplegia, a rapid re-education is often quite enough by itself, but as a rule the patient will have greater confidence if he has received some preliminary suggestive treatment.

\section{Suggestive Treatment and Re-education.}

For this reason the method which we have finally adopted consists in a very brief suggestive treatment followed by rapid re-education, which is continued, if possible, without a pause until the normal function is entirely regained. The details will be discussed in dealing with the different functional manifestations, but there are certain general considerations which hold good in every case.

The suggestive treatment may take any form, but it is essential that the patient should be convinced that it will produce an immediate recovery. In untreated cases there is rarely any difficulty in this, and the conviction can be strengthened by using a form of treatment which will be capable by itself of evoking some part of the function which is temporarily in abeyance. For instance, a case of mutism may be cured by tickling the back of the mouth so as to induce reflex phonation. The patient is compelled to make a noise, and the fact that he has done so will convince him that the treatment will be effective. In the same way a strong electric stimulus will prodnce a sensation and motion in a limb which is supposed to be anæsthetic and paralysed, and this in itself will be enough to convince the patient that he is on the road to recovery. Occasionally this form of treatment has been tried before and has failed because the

2 Cf. Hurst : Medical Diseases of the War, 1916

3 Dubois : Psychic Treatment of Nervous Disorders. operator had not enough confidence in the method. In this case it is, of course, useless to repeat the same procedure, and we must fall back on some other form of treatment in which the patient will have greater faith.

The simplest form of suggestive treatment to apply is the faradic current. The therapeutic uses of electricity are still mysterious enough to the layman, and nearly every patient is willing to accept the suggestion that some form of electricity will cure him. The current can be made extremely painful if it is necessary to supply the disciplinary element which must be invoked if the patient is one of those who prefer not to recover, and it can be made strong enough to break down the unconscious barriers to sensation in the most profound functional anæsthesia. The only difficulty arises when the patient has already been subjected to a long course of -electrical treatment without result. It often happens that a patient, either from mistaken diagnosis or mistaken ideas of treatment, has been given daily applications of some innocuous form of electricity in the belief that the electricity by itself will do all that is necessary. Such treatment, unaccompanied by the necessary suggestions, is generally quite useless in a functional case, and, as a rule, the only result is to accustom the patient to electrical stimuli and to foster the idea that his case is hopeless. It is easy to satisfy one's self that in these cases the sole value of electrical treatment lies in the suggestive effect it can be made to produce. We have watched a nurse administering the treatment to a paralysed limb, rolling the electrode up and down, sometimes with eyes shut and sometimes with eyes open, to say nothing of an occasional yawr.. Needless to say, the patient remained paralysed, and the only result was so much current wasted. On the other hand, the same patient given exactly the same form of electricity with persuasion recovered completely in a few minutes.

When the patient tells us that he has already been treated by electricity it is as well to find out whether the treatment was painful or not. If it was not, the patient will generally yield at once to painful faradisation with a wire brush after he has been informed that this kind of electricity is far more potent than any he has had previously. If this, too, has been tried before, the suggestive treatment must take an entirely different form. As an instance of this we may quote the case, recently treated by one of us, of an officer who had a functional paralysis of the arm which had persisted for two years in spite of prolonged treatment by hypnotism, psycho-analysis, rest, massage, anæsthesia with ether, and electrical treatment which had included several extremely painful applications of electricity to the arm. He knew something of the functions of the brain and took a great interest in his condition, which he was prepared to discuss exhaustively. He was told that he had come to be cured, and that for the present he must be content with this; the nature of the cure would be explained to him afterwards. Without any further discussion the motor areas of the cortex were mapped out roughly, the measurements being repeated aloud to impress and mystify the patient. He was told that as soon as the shoulder area of the cortex was stimulated by faradism he would be able to raise his shoulder and that the rest of the arm would recover in the same way. A very mild faradic current was applied for a few seconds to the scalp, and he was then ordered to move his shoulder. He did so at once, and in a few minutes the whole of the paralysis had disappeared and he could raise 30 pounds. We believe that the success in this case was due in a large measure to the fact that the patient was not allowed to discuss his case or to criticise the proposed treatment. The value of this will be pointed out immediately.

Whatever form of treatment is employed, the patient must be convinced that the physician understands his case and is able to cure him. This idea should be fostered from the moment the patient enters the ward. The case is investigated as briefly as possible, and each physical sign is accepted as perfectly normal in the circumstances, and not as in any way interesting or obscure. The best attitude to adopt is one of mild boredom bred of perfect familiarity with the patient's disorder, and if the case has to be exhibited to anyone else it is shown not as anything unusual, but as a perfect example of the type of case which is cured in five minutes by appropriate treatment. After the examination the patient is met with the absolute assurance that 
he will be cured as soon as the physician can find the time to treat him. He is told that he will not need to stay in hospital for more than a few days, and that he can write and inform his friends of this. It is usually necessary to find out what treatment the patient has had before to avoid the risk of repeating a procedure which bas already been tried and found wanting, but apart from this it is better to avoid discussing the case and the methods which will be adopted to cure it. The barest statement should suffice, and the patient should be silenced at once if he attempts to air his own views on the subject. An argument in which the physician does not seem perfectly sure of his ground is likely to weaken his authority at the moment when it should be absolutely unquestioned, and an air of complete assurance is far more convincing than the most elaborate reasoning.

The treatment is best carried out in a special room set apart for the purpose, where there will be nothing to distract the patient's attention. As soon as the least sign of recovery has appeared the re-education is begun. The patient is given no time to collect his thoughts, but is hurried along by a mixture of persuasion and command until the disordered function has completely recovered. The patient is never allowed any say in the matter. He is not asked whether he can raise his paralysed arm or not; he is ordered to raise it, and told that he can do it perfectly if he tries. Rapidity and an authoritative manner are the chief factors in the re-educative process, and in every case an effort should be made to produce complete recovery before the patient goes back to the ward. If the treatment has to be discontinued before recovery is complete the patient should be assured that he will be quite well in 24 hours and the re-education should be continued as soon as possible.

There are many details which are best considered in connexion with particular hysterical symptoms, and therefore we shall describe the most common affections in which the suggestive method is pre-eminently successful. The most common disorder is the complete or partial loss of a normal function, and the most common functions to be lost are those concerned with hearing and speaking and with the sensation and motion of the limbs.

\section{Deafness.}

As a rule, the patient is stone-deaf and often dumb as well and there may be associated symptoms, such as loss of vibration sense in the bones of the skull. The patient is told in writing that he will be cured in five minutes by electricity. The suggestive effect may be enhanced by the use of a darkened room, a head mirror, and so forth, but the essential treatment consists in applying a strong faradic current to the side of the head or to the external auditory meatus. The patient is informed that as the feeling comes back the current will appear more and more painful, and that in a very short time he will be able to hear the tick of a watch pressed against his ear. The current is applied for a few seconds at a time and increased in strength between each application. When the patient begins to show signs that the current is painful he is told that the feeling is returning and that he will soon hear perfectly. A watch (or a tuning-fork) is pressed closely against his ear between each application of the current and in less than five minutes he will begin to hear it. After a few more applications of the current he will be able to hear the watch at a distance of a foot or more. Sometimes he is able to hear the ticking of a watch, but is unable to interpret what is said to him. He is then reeducated, beginning with the vowel sounds, then with words of one syllable, then two, and so on, until he can hear perfectly. If the other ear has not recovered at the same time it is a simple process to restore the hearing to it in the same way. The cure is usually complete in less than ten minutes, though it may take longer in patients who have been stonedeaf for a year or more. In a series of 34 cases we have had only one failure. This was in a patient whơ had been deaf for over a year in spite of every kind of treatment. We saw him for a few minutes only and had no opportunity of continuing the treatment.

We have yet to observe any of the unpleasant after-effects which are said to arise from faradism in the region of the ear. It may produce a transient vertigo, and if it is to be effective it must be strong enough to be painful. The patient may object to this at first, but when the hearing has been restored to one ear he is always perfectly ready to have the same process applied to the ear which is still deaf.
One has sometimes to deal with cases where faradism has failed to produce a cure, The failure is due to lack of determination on the part of the operator; he is either ignorant of the fact that the condition is one which always responds to suggestive measures, or he becomes too easily fatigued to see the thing through to a successful issue. In such cases some other suggestive measure must be adopted; for instance, the application of tuning-forks of different sizes, beginning with those in which the vibrations are slow enough to be felt rather than heard, and reducing the size gradually until the fork can be heard rather than felt. The re-education can then be completed by shouting down a stethoscope. How ever, in untreated cases we have found the electrical method to be invariably successful in a few minutes.

\section{Mutism.}

When this is complicated by deafness it is, of course, natural to treat the deafness first, as this makes communication with the patient so much easier. As soon as he can hear the patient is told that his speech will be restored in the same way. A long pharyngeal electrode is used, and he is told to sound the vowel "ah" as soon as he feels the current. The soft palate and pillars of the fauces are stimulated, and as a rule he phonates loudly as soon as the electrode is applied; he is then told to repeat the other vowels, the letters of the alphabet, numbers, days of the week, \&c., and he is soon able to enter into a conversation.

When mutism has existed alone it is often unnecessary to do anything more than tickling the back of the patient's mouth with a mirror or tongue depressor. This evokes some reflex phonation in the form of gurgling or retching, and the patient is then told to say "Ah." The process is repeated until he can do this naturally, and it is then a simple matter to make him sound the other vowels and to repeat the whole alphabet in an audible voice. In still milder cases the patient will phonate loudly when he coughs or gargles, and he can then be made to sound "ah" by gradually eliminating the explosive element of the cough. In some cases the soft palate appears to be anæsthetic, and the patient does not phonate when his throat is tickled. This difficulty can be overcome by applying a faradic current to the back of the throat. In a case which has been previously treated with electricity in this way some new form of treatment must be devised and every effort must be made to strengthen the suggestive effect. However, the condition is one which tends to clear up spontaneously, and most cases respond at once to the simplest suggestions.

The first signs of voluntary phonation must be followed ap immediately, and the patient must be given no respite until he can speak perfectly. He is, of course, instructed beforehand that the treatment will effect a complete cure, and he must not be allowed to go back to the ward whispering or stammering, even though he may regard this as an immense improvement on his former state.

\section{Aphonia.}

The patient is able to whisper, but cannot phonate properly. This may exist as a stage in the spontaneons recovery of a mute, but it is most often an after-effect of laryngitis. The patient can be made to phonate by tickling his throat or by conghing or gargling, and the whole process is simply one of re-education, which is usually complete in a minute or less. It is rarely necessary to use electricity.

\section{Stammering.}

A tendency to stammer sometimes shows itself during the re-education of a mute. It can be checked at once by reeducation and simple suggestive measures, such as faradism applied to the back of the neck, but if it is not checked as soon as it appears it may become much more intractable. For this reason patients who have been allowed to recover their voice spontaneously may develop a bad stammer which takes some time to clear up.

\section{Blindness.}

We have no direct experience of hysterical blindness in both eyes in military cases. Cases of monocular blindness or of defective vision, with no refractive error and no changes in the retina, are probably more often the result of malinger. ing than of hysteria. Treatment by strong faradism in the region of the supra- or infra-orbital nerves is successfal in either case, but it is generally found that the alleged defect can be remedied by a little plain speaking. 
Hysterical affections of the other special senses and of the cranial nerves are relatively unimportant, and there is usually no difficulty in devising a suitable form of suggestive treatment.

\section{Paralysis of the Upper Limbs.}

Cases of paralysis of one arm are very common and very easily curable. As a rule they occur after some slight wound or bruise which has necessitated the use of a splint. The treatment can best be described by considering a typical case. The patient has received a slight wound of the forearm some months ago, and ever since his whole arm has been useless. He can move it slightly at the shoulder by exerting what appears to be a superbuman effort, and he can occasionally flex the fingers through a small angle. There is complete anæsthesia of the hand and arm, ending in a line drawn horizontally round the elbow. The patient does not necessarily complain of this anæsthesia and there may be no sign of its existence until it is suggested to him by the physician, but it is often useful to elicit it in view of the subsequent treatment. The diagnosis is obvious at once from the absence of wasting, the distribution of the sensory loss, and the involvement of the whole arm after an injury which could not possibly have affected the upper arm and shoulder.

The patient is told that he is very lucky to have come off with such a slight injury, and that his arm will be set right in five minutes by the application of a special form of electricity. He is made to sit on a large pad electrode connected with an induction coil, the other terminal being connected with a wire brush. He is informed that the first effect of the current will be to bring back the feeling in the forearm, and that as the feeling returns the power will return with it. A fairly strong current is turned on, and the wire brush is drawn downwards over the forearm from the elbow to the wrist. After a few applications the patient is told that he can now feel as far down as the wrist, and he is tested with a pin to convince him of the truth of this. If he cannot feel the pin-prick, the current is increased in strength until he can do so. The same process is applied to the hand until this, too, ceases to be anæesthetic. The improvement is pointed out to the patient and he is told that as the feeling has now returned to his arm it will be a very simple matter to restore the power of movement. ${ }^{4}$ After a few touches with the electrode designed to produce contraction in the muscles he is told to move the arm. He will do so at first in a hesitating manner with every appearance of great effort, but this will be quite enough to convince him that the power is really returning. The rapid re-education follows at once. $\mathrm{He}$ is given no time to think, but urged to move the arm more and more strongly, to grip the physician's hand, to flex and extend the elbow, \&c., and the pressure is not relaxed until the whole limb has returned to its normal vigour. If the improvement comes to a standstill before recovery is complete, the faradisation is repeated with stronger and stronger currents. Rapidity and an air of authority which will brook no denial are usually quite enough without this, and if once the recovery is complete there will be little fear of a relapse. If the patient's manner suggests that he is likely to relapse as soon as he leaves the hospital, he is told that this is very unlikely, but that if it should occur he should report sick at once and come back for treatment with a current far stronger than that already used. Needless to say it is rarely necessary to carry out this proposal.

In untreated cases a very mild current is all that is required, but if, as often happens, the patient has been treated before with some form of electricity without suggestion it is better to begin with a current strong enough to be painful. If this has already been tried without success, it is better to adopt some entirely different line of treatment, as in the case of the officer already quoted.

Paralysis of the Lower Limbs.

Cases of monoplegia are treated in the same way as paralysis of one arm. In paraplegia the treatment depends to some extent on the type of paralysis. As a rule, a recent

4 The layman seems to consider that loss of power and loss of feeling are inseparably connected. One of us asked 100 persons of average intelligence whether they would lose the sensation in their hand if suggesting the answer, but in every case they replied in the affirmative. This idea may account for the development of anæs thesia in functiona paralysis, and it is easy to see that a patient will accept the suggestion that his paralysis will recover when his anesthesia has been cleared up by electricity. case of paraplegia due to "shell shock" or burial belongs to the flaccid type without exaggerated reflexes. If this is allowed to recover slowly it merges into the spastic variety with pseudo-clonus, exaggerated knee-jerks, and rigidity. Passive movements are resisted strongly, and when the patient attempts to put the flexor group of muscles into action the extensor group contracts at the same time and a condition of increased tone and clonus is set up. The condition is, of course, due to a disordered mental process and not to organic diseases in the central nervous system, and we may regard it as akin to the states of negativism which occur in dementia præcox. Whatever the explanation may be, the fact remains that this condition is very often seen in cases which have been badly treated, and in such cases it is often difficult to eradicate completely in a short time. The spastic condition often occurs during the re-educative treatment of a case of flaccid paraplegia, but it is then of little consequence, as the patient is allowed no time to acquire the habit.

In cases of flacsid paraplegia it is as well to restore sensation and movement to the limbs by treatment with faradism before the re-education is attempted. Otherwise the patient will simply collapse when set on his feet. In the spastic type it is often better to hold the suggestive treatment in reserve and to do as much as possible by reeducation alone. The patient is told that all he needs is a little confidence in his legs, and he is then set on his feet and induced to walk. At first the greater part of his weight is taken by the physician, but in a few minutes he is made to bear his own weight and to walk with less and less assistance and more and more rapidly.

Certain details in the treatment deserve mention. It is perhaps unnecessary to insist that slippers without heels are not the ideal form of footgear when the patient is learning to walk. They encourage a shuffling gait, and frequent halts are necessary to readjust them. Indeed, the use of slippers and a stick would perpetuate a limp in any patient who had the least tendency to a neurosis. The re-educative treatment of a patient who cannot walk properly is best carried out in a large empty room, a corridor, or out of doors. He will not feel unduly self-conscious as he would do in a ward full of patients, and he will have nothing to hold on to. If there is no alternative between walking and falling down the patient will usually find himself able to walk (once he has passed the earliest stages in re-education), but if a middle course is offered in the shape of a chair or a bed to which he can cling he will at once seek safety in this, and the more he is allowed to use his hands to support himself the less likely will he be to trust to his legs. At first the patient will seem to be continually on the verge of losing his balance, but, as a rule, there is little fear of this, and the idea should not be encouraged by supporting him whenever he seems in the slightest danger of falling. It is best to allow him as little assistance as possible. To begin with he should walk armin-arm with the physician, then facing him and holding his hands, then holding one hand only, and finally with no support at all. A fall should be avoided as far as possible, but it is of no great consequence if it does occur, for the patient will not be taken unawares, and will be unlikely to hurt himself. A fall should on no account be taken as an excuse for resting; it should be treated as a matter of course, and the patient should be made to continue his efforts until he can walk without falling.

If possible the patient should not be returned to the ward until he can walk without assistance of any kind, and on no account should he be allowed to use sticks or crutches, even though he has been paraplegic for six months. Until he has recovered completely he should not be allowed to walk except under the direct supervision of the physician; otherwise he will be liable to develop a functional gait or a limp, and a further re-education will be necessary. As in every functional disorder, it is extremely important to produce a rapid improvement during the first treatment and to continue this at the earliest possible moment until recovery is complete.

Precisely the same form of treatment applies to the patient with functional "rheumatism," who walks with bent and trembling iznees and a couple of sticks, functional hemiplegia, functional sciatica, and functional gaits of all kinds. As a rule it is found that the more serious the disability the easier will it be to cure; a case of complete 
flaccid paraplegia will often walk perfectly after an hour's treatment, whereas a man with a slight functional limp will need a re-education lasting for days or even weeks.

$$
\text { Tremors, Fits, \&c. }
$$

We have given a detailed account of the treatment of deafness, mutism, and paralysis because these cases are so easily curable with rapid suggestive and re-educative measures. They are all due to the absence or diminished activity of a normal function, and the treatment has only to recall this function to the patient's consciousness. Fortunately these cases form a large percentage of the hysterical war neuroses. There is, however, a group of cases in which the treatment is often successful, but by no means invariably. These cases depend not so much on the absence of a normal function as on its excessive and disordered activity. Functional tremors and incoördination, choreiform movements, and tic-like spasms are examples of this class, and we might include hysterical fits and even the stammering and explosive type of speech. Functional tremors are sometimes very easily cured by a little suggestive faradism, and fits may be stopped temporarily at least by suggestive measures. The patient is induced to have a fit by assuring him that he will do so when an electric current is applied to his forehead, and the fit is checked by supraorbital pressure or faradism to some other part of the body. The patient is then told that his fits are not epileptic and that they have been cured. As a rule he will have no more fits as long as he is in hospital, but he may relapse outside, and we know of several cases where this has happened. Indeed, the method is probably more valuable as an aid to diagnosis than to treatment.

Involuntary movements and hysterical chorea may yield to rapid suggestive methods, but isolation is a more reliable form of treatment, although it is at the best a slow process.

Functional contractures deserve a place by themselves. When they are truly hysterical they will usually yield at once to suggestive faradism with a moderately strong current. But it is sometimes extremely difficult to make certain that the condition has not some organic basis. Babinski and Froment have collected a number of cases described as reflex nervous disorders and having an organic origin, although they show a superficial resemblance to the hysterical contractures. $^{5}$ These cases are generally intractable, and so far no line of treatment has been found to have much effect on them. We have seen four or five cases which could be included in this category, and in them suggestive treatment was certainly quite ineffective.

For the sake of completeness we should mention a method of suggestion which is often employed with good results. This consists in anæsthetising the patient and making the necessary suggestions to him as he is going under or coming round from the anæsthetic. To a certain extent the process may be compared with hypnotism in that the suggestions are made at a time when the critical faculties of the patient are dulled; but the main advantage of the method lies in the fact that in the stage of excitement the patient will struggle, cry out, \&c., and that he will often regain consciousness whilst he is in the act of moving the arm which was formerly paralysed or using the voice which was formerly dumb. The method demands an anæsthetist who will be able to produce a long excitement stage, and the results are to some extent a matter of luck. This furnishes the chief objection to the method, for if it fails the patient will have some excuse for taking a gloomy view of his case, and he will be naturally sceptical of less heroic methods. However, we have little direct experience of the method, as we have not found it necessary to employ it.

\section{Prognosis and After-treatment.}

The treatment of a functional case does not end at the moment when the disability has been cured, and we have always to determine how much the patient may be safely called upon to do without fear of a relapse. This will depend on how far the underlying mental condition is a permanent state and how great a strain was necessary to lead to the development of the symptoms. If the patient gives a history showing pronounced mental instability or previous functional troubles before the war, and if he has lost the use of his legs after a few days in the trenches, it is

5 Babinski et Froment: Hystérie-Pithiatisme et Troubles Nerveux d'Ordre Réflexe. Masson et Cie. 1917.

clear that he will never be of the least value at the front, and he is probably best employed in a labour unit at home or on sedentary work. If he has served several months in the fighting line, and has then lost his voice after a week without sleep and a severe bombardment, he will often be perfectly fit again after a short rest, and he will show only the slightest signs of the hysterical temperament. He may relapse under an equally severe strain, but if his cure has been rapid and complete on the first occasion he will have less reason to fear a relapse and to regard a temporary loss of speech as a serious and intractable condition. It is another matter if he has been allowed to remain dumb for six months in hospital, for in this case he will have every reason to regard himself as the victim of a severe form of "shell shock," and he will probably be quite unfit for service in the fighting line.

In all cases a thorough examination of the past history and mental condition must be made before we can decide what form of service will be most advantageous to the patient and to the nation. In the more intractable conditions-tics, convulsions, \&c.--the patient may be able to do some useful work with a labour unit, but it is often better for all concerned to return him to civilian life.

In conclusion, we wish to express our thanks to the medical and surgical staff of the National Hospital, Queen. square, and to Lieutenant-Colonel W. Turner, offeer in charge of the Connaught Hospital, Aldershot, for permission to publish these notes.

\section{CHYLO-HAMOTHORAX FROM WOUNDS INVOLVING THE THORACIC DUCT.}

BY T. R. ELLIOTT, F.R.C.P.LOND., F.R.S., LIEUTENANT-COLONEL, R.A.M.C. AND

HERBERT HENRY, M.D. LOND., CaPTAIN, R.A.M.C.

Wrien a fluid obtained by exploratory puncture of the chest seems to be "frankly purulent" to the naked eye one is apt to assume that this appearance is sufficient proof that an empjema is present and that rib resection is justified without any further microscopic study of the specimen.

In nearly all such cases the presumption that infection exists is true, but occasionally a rare example may be encountered in which the thoracic duct has been wounded in the chest without the associated injuries being at once fatal, and then the milky chyle will leak into the effused blood and produce a combination mimicking that of a pyo-hæmothorax so closely that most surgeons would be deceived by it.

The first case quoted in this paper was one in which the error was not avoided and the medical officer was misled by the appearance of the fluid into performing an operation for drainage of the pleural cavity. The patient recovered, but his convalescence was dated by months instead of by weeks in consequence of the mistake. In the second case the character of the fiuid was guessed to be chylous and proved to be so before anything was done. But unfortunately the effusion had been infected by the shell fragment which caused the wound and drainage was unavoidable and was followed by death.

The error can only be avoided by holding fast at all times to the general clinical rule: "That drainage of a chest after gunshot wound should never be undertaken except apon bacteriological proof of infection in the fluid withdrawn at exploration, or upon the recognition of an offensive smell in the latter." The naked-eye appearance of any fluid may be entirely misleading, as hopelessly, though not so frequently, as is the clinical judgment of a chest wound before exploration is made.

At base hospitals these cases of chylo-hæmothorax must be very few. The two that are described from our own experience did actually occur in the same hospital within a month of one another, but they are the only two that we have seen out of a total of 600 samples of hæmothorax fluid that were examined by us in the laboratory; and this laboratory figure covers a clinical experience of far more than a thousand chest wounds. But the occurrence of a chylous effusion would not appear to be so rare as this, if it were expressed as a percentage of all large effusions on the 